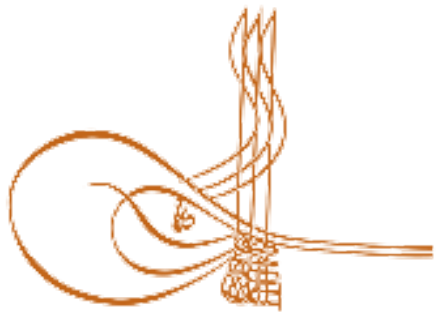

www.turkishstudies.net/education
Turkish Studies - Educational Sciences

eISSN: $2667-5609$

Research Article / Araştırma Makalesi

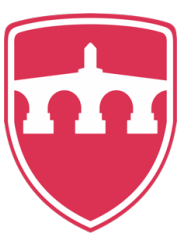

INTERNATIONAL

BALKAN

UNIVERSITY

Sponsored by IBU

\title{
Robotik Destekli Uygulamaların Akademik Başarı ve Bilimsel Süreç Becerilerine Etkisi: 4. Sınıf Fen Bilimleri Dersi Örneği
}

\author{
The Effect of Robotic Integrated Activities on Academic Achievement and Scientific Process Skills \\ of Students: A Case Study of 4th Grade Science Course
}

Abdullah Koray ${ }^{*}-$ Serkan Çakı**

\begin{abstract}
The purpose of this research is to investigate the effect of the robotic integrated activities on students' academic achievement and scientific process skills in the science lesson of the fourth graders at "Microscopic Living and Environment" unit. In order to test the research problems, semi-experimental method and pretestposttest control group design were used. The research sample consists of 87 students at the fourth grade level of a public school in a district center in the Western Black Sea region. The study was performed over a sixweek period in the 2016-2017 academic year and 44 of the students were selected as the control group and 43 of the students as the experimental group. While the students in the experimental group were thought with robotic integrated activities, the control group students were trained based on the standard curriculum in 2017. "Academic Achievement Test" and "Scientific Process Skills Test" were used as pretest and posttest for experimental and control groups. Data were analyzed by t-test for dependent and independent groups in SPSS software. According to the findings of the study, it was concluded that the academic achievement and scientific process skills of experimental group students using robotic integrated activities increased. Similarly, it was observed that the academic achievement and scientific process skills of the control group students using the methods appropriate to the Science course (4th grade) curriculum increased. When academic achievement and scientific process skill achievement scores were examined, it was seen that the scores of the experimental group were higher than those of the control group. However, there is no statistically significant difference.
\end{abstract}

\footnotetext{
Bu makale Dr. Öğr. Üyesi Abdullah KORAY'ın danışmanlığını yaptığı Serkan ÇAKIR'ın yüksek lisans tezinden üretilmiştir. Çalışma verileri 2016-2017 eğitim öğretim yılında toplanmıştır.

Bu çalışma 27-30 Nisan 2018 tarihleri arasında Nevşehir'de düzenlenen X. Uluslararası Eğitim Araştırmaları

Kongresinde sunulmuştur.

${ }^{*}$ Dr. Öğr. Üyesi, Zonguldak Bülent Ecevit Ü., Ereğli Eğitim Fakültesi, Matematik ve Fen Bilimleri Eğitimi Bölümü Asst. Prof. Dr., Zonguldak Bulent Ecevit University, Ereğli Faculty of Education, Mathematics and Sciences Department ORCID 0000-0002-2972-1317

korayabdullah@gmail.com

** Öğretmen, Karadeniz Ereğli Bilim ve Sanat Merkezi

Teacher, Karadeniz Ereğli Science and Art Center

ORCID 0000-0001-8543-2950

Serkan1622@gmail.com
}

Cite as/ Atıf: Koray, A. \& Çakır, S. (2020). Robotik destekli uygulamaların akademik başarı ve bilimsel süreç becerilerine etkisi: 4. sınıf fen bilimleri dersi örneği, Turkish Studies - Education, 15(2), 1073-1087. https://dx.doi.org/10.29228/TurkishStudies.40440

Received/Geliş: 06 January/Ocak 2020

Accepted/Kabul: 27 April/Nisan 2020

Checked by plagiarism software

Copyright (C) INTAC LTD, Turkey 
Structured Abstract: Introduction: Educational Robotics has emerged as a teaching area that nurtures students' interest and curiosity, offers practical and entertaining activities at the same time in an interesting learning environment where robots are used as materials (Eguchi, 2010). Despite the fact that robotics has a high potential to contribute to education, it is very difficult to provide the expected benefits with simple robotics demonstrations in classrooms. The important point is that such applications can be integrated correctly in the curriculum (Alimisis, 2013). The aim of this study is to reveal whether the robotic supported applications prepared for the achievements of the 4th Class Science course "Microscopic Creatures and Our Environment" unit have an effect on students' academic achievement and scientific process skills. The study was based on a subject-based curriculum approach. Activities based on research and inquiry is designed in accordance with the acquisitions.

\section{Research Questions}

1. Is there a significant difference between the experimental group in which the robotic applications are made and the control group where the education is taught in accordance with the curriculum in terms of academic achievement gain (difference between posttest and pretest) variable?

2. Is there a significant difference between the academic achievement pretest and posttest scores of the experimental group?

3. Is there a significant difference between the academic achievement pretest and posttest scores of the control group students?

4. Is there a significant difference between the experimental group and the control group in terms of scientific process skills gain variable?

5. Is there a significant difference between the scientific process skills pretest and posttest scores of the experimental group?

6. Is there a significant difference between the scientific process skills of the control group students in terms of pretest and posttest? applications?

7. What are the opinions of the experimental group students about robotic supported

\section{Method}

In order to test the research problems, semi-experimental method and pretest-posttest control group design were used. The independent variable whose effect on the "academic success" and "scientific process skills" dependent variables is "robotic coding applications". Each activity using teacher instructions and student worksheets prepared for the experimental group requires the use of LEGO ${ }^{\circledR}$ WeDo TM robotic sets. The same activities for the control group were adapted so as not to require the use of robots. The practices for unit acquisitions continued for four weeks, 3 hours a week, as prescribed by the curriculum. During the data collection process, Academic Achievement Test, Scientific Process Skills Test and student diaries were used. Quantitative data of both groups show normal distribution according to the ShapiroWilk normality test since the number of students is below 50. The data were analyzed by t-test methods for dependent and independent groups from the parametric statistics in the SPSS package program. Qualitative data obtained from student diaries were analyzed by descriptive analysis method.

\section{Results and Discussion}

No significant difference was found between the experimental and the control group in terms of academic achievement gain scores. However, it was concluded that the academic achievement gain points of the experimental group students were higher than the academic achievement gain points of the control group students. Similar results were obtained by Hussain et al. (2006) and Lindh and Holgersson (2007). When the research findings are examined, it is concluded that there is a significant difference between the academic achievement pre-test and post-test scores of the experimental group and control group students. Posttest academic achievement scores of both groups were higher than pretest academic achievement scores. According to this result, both robotic coding practices and methods suitable for the curriculum have been effective in increasing students' academic success. The use of similar activities prepared according to structured research 
questioning in both groups is thought to be effective in the absence of a significant difference between academic achievement gain scores.

There was no significant difference between the experimental group and the control group in terms of scientific process skill gain scores. However, it was concluded that the scientific process skill gain points of the experimental group students were higher than the scientific process skill gain points of the control group students. In addition, it was concluded that there was a significant difference between the experimental group and the control group students' scientific process skill pretest and posttest scores. Posttest scientific process skill scores of both groups were higher than pre-test scientific process skill scores. According to this result, both robotic coding practices and methods suitable for the curriculum were effective in increasing students' scientific process skills. The use of similar activities prepared according to structured research questioning in both groups is thought to be effective in the absence of a significant difference between the scientific process skill gain scores. Considering other studies in the literature, it is possible to find different findings (Lindh and Williams et al., 2007; Şenol \& Böyük, 2015; Özdoğru, 2013).

According to the data obtained from student diaries, it can be concluded that in the first weeks the students focus on the robot-making process instead of the subject acquisitions. In the coming weeks, they perceive the activity as a game by writing different codes instead of focusing on the subject acquisition. The reason for the lack of a significant difference between the academic achievement gain points of the experimental and control groups can be explained as the coding process over the teaching process in line with the findings obtained from the student diaries.

Saraçoğlu et al. (2012) stated that the scientific process skills acquisitions were not represented in close proportion among the 4 th and 5th grade science and technology course achievements. In this study, the absence of a significant difference between the scientific process skills access points of the experimental and control groups can be explained by these findings in the literature. In addition, since the robotic supported activities are prepared in accordance with the 4th grade level, they do not develop many of the integrative scientific process skills.

\section{Suggestions:}

In order to prevent the robot coding process from preventing the subject gains, the coding skills can be increased by enabling students to spend more time with the robot sets outside the Science course. Thus, students' academic success can be increased by reducing the time they spend for coding and focusing on the acquisitions. Considering that the level of acquiring scientific process skills increases as the grade level increases, it is possible to work with higher classes, by determining appropriate topics. Attention should be paid to the possibility of developing integrative scientific process skills when designing activities. The process applied can be repeated with students whose academic achievement and scientific process skills are different. Thus, the effects of robotic supported applications on students' academic achievement and scientific process skills can be examined in more detail.

Keywords: Science Education, Robotics, Academic Achievement, Scientific Process Skills, Robotic Based Science Activity.

Öz: Bu araştırmanın amacı, Fen Bilimleri dersi 4. Sınıf "Mikroskobik Canlılar ve Çevremiz” ünitesinde robotik destekli uygulamaların akademik başarı ve bilimsel süreç becerisi değişkenlerine etkisini incelemektir. Araştırma yarı deneysel yöntemlerden öntest-sontest kontrol gruplu desen kullanılmıştır. Araştırma örneklemini Batı Karadeniz bölgesinde bir ilçe merkezinde bulunan bir devlet okulunun dördüncü sinıf seviyesindeki toplam 87 öğrenci oluşturmaktadır. Çalışma 2016-2017 eğitim öğretim yılında, altı haftalık bir sürede uygulanmış ve öğrencilerin 44'ü kontrol 43'ü deney grubu olarak seçilmiştir. Deney grubundaki öğrencilere robotik destekli etkinlikler uygulanırken, kontrol grubu öğrencilerine 2017 y1lı Fen Bilimleri Dersi Öğretim Programının öngördüğü etkinlikler uygulanmıștır. Her iki grupta ön test ve son test olarak "Akademik Başarı Testi" ve "Bilimsel Süreç Becerileri Testi" kullanılmıştır. Veriler SPSS paket programında bağımlı ve bağımsız gruplar için t-testi ile analiz edilmiştir. Çalışmadan elde edilen bulgulara göre robotik destekli etkinliklerin kullanıldığ 1 deney grubu öğrencilerinin akademik başarılarının ve bilimsel süreç becerilerinin arttığı görülmüştür. Benzer bir şekilde Fen Bilimleri dersi (4.sınıf) öğretim programına uygun yöntemlerin kullanıldığı kontrol grubu öğrencilerinin de akademik başarılarının ve bilimsel süreç becerilerinin arttığı 
gözlemlenmiştir. Akademik başarı ve bilimsel süreç becerisi erişi puanları incelendiğinde, deney grubunun kontrol grubundan daha başarılı olduğu belirlenmiş ancak aradaki farkın istatistiksel açıdan anlamlı olmadığı ortaya konmuştur.

Anahtar Kelimeler: Fen Eğitimi, Robotik, Akademik Başarı, Bilimsel Süreç Becerileri, Robotik Temelli Fen Etkinliği.

\section{Giriş}

Son yıllarda gelişen teknolojiyle birlikte, her alanda ortaya çıkan problemlerin çözümünde ve ihtiyaçların karşılanmasında robot teknolojisinin etkin kullanımı gündeme gelmiştir. İnsan yaşamını kolaylaştırıcı olarak, laboratuvar çalışmalarından günlük yaşam aktivitelerine kadar bütün alanlarda kullanılan bu teknoloji, eğitim alanında da kullanılmaya başlanmış, çocukların robot teknolojisini öğrenmeleri çok küçük yaşlardan itibaren desteklenmeye çalışılmıştır. (Felicia ve Sharif, 2014). 1940'l1 yılların başında Isaac Asimov robot kelimesinden, robot teknoloji ile ilgili bütün alanları kapsayan "robotik" kelimesini türeterek ilk kez kullanmıştır. Robotik, robotların çalışma ve kullanımını ifade eden bir terimdir (Koç \& Böyük, 2013). Bir başka deyişle Robotik, robotlarla ilgili yapılan inşa etme, programlama ve tasarım süreçlerini içeren bir teknoloji dalıdır (Erbaş, 2014). Elektronik, mühendislik, mekanik gibi alanlar başta olmak üzere birçok alanda, robot tasarlanması üzerine çalışan teknoloji alanıdır (Şenol, 2012). Son on y1l boyunca robotik, eğitim araştırmacıları ve öğretmenlerin de ilgisini çekmiş, okul öncesi dönemden üniversiteye kadar olan eğitimlerinde tüm öğrencilerin bilişsel ve sosyal becerilerini geliştiren, fen bilimleri, matematik, teknoloji, bilişim alanlarındaki öğrenmeleri ve disiplinler arası etkinlikleri destekleyen değerli bir araç olarak görülmüştür (Alimisis, 2013). Eğitsel robotik olarak isimlendirilen bu alanda son y1llarda yapılan çalışmalarla öğrenme ortamları yeniden dizayn edilmeye çalışılmıştır.

Eğitsel Robotik, materyal olarak robotların kullanıldığı ilgi çekici bir öğrenme ortamında, öğrencilerin ilgisini ve merakını besleyen, uygulamalı ve eğlenceli aktiviteler sunabilen aynı zamanda kodlama becerisi kazandıran bir öğretim alanı olarak ortaya çıkmıştır (Eguchi, 2010). Eğitsel robotik etkinlikleri yapılandırmacı, probleme dayalı, projeye dayalı gibi farklı yaklaşımlara entegre edilebilmektedir (Benitti, 2012). Hangi yaklaşımlar kullanılırsa kullanılsın, uygulama başlangıcında robot setlerinin öğrenciler tarafından tanınabilmesi için genellikle üretici tarafından tasarlanan etkinlikler küçük gruplarla (2-4 kişi) uygulanmaktadır. Böylece öğrenciler robot setlerinin parçalarını tanımış ve programlama dilini de öğrenmiş olur. Daha sonraki aşamalarda amaca uygun olarak etkinlikler tasarlanmaktadır. Bu etkinliklerin robotiğin doğası gereği, donanımsal ve yazılımsal olmak üzere iki boyutu vardır. Etkinlikler sınıf düzeylerine uygun olarak, tam yapılandırılmış tek çözümlü olabileceği gibi, öğrencilerin performansına göre şekillenen tamamen açık uçlu da olabilmektedir.

Robotik, çocukların öğrenmelerini motive etmek için kullanılabilecek muazzam bir enerji kaynağı olmasının yanı sıra, temelde, kavramların ya da konuların öğretilmesine katkı sağlamak ve beceri geliştirmek için de kullanılabilir (Benitti, 2012). Eğitsel Robotiğin eğitim alanında nasıl kullanıldığı ile ilgili, literatürde üç farklı yaklaşımdan bahsedilmiştir (Eguchi, 2010). Bunlardan ilki olan konu temelli öğretim programı yaklaşımına göre, öğretim programı, öğrenme alanları için özel bir konu etrafında birleştirilir ve çoğunlukla uygulamalar araştırma ve iletişim yoluyla şekillenir (Williams vd. 2007, Mitnik vd. 2008, Sullivan 2008 ). Proje temelli yaklaşıma göre ise; öğrenciler robotik uygulamaları gruplar halinde yaparak, gerçek dünyadaki problemleri keşfetmek için çalışırlar (Hussian vd., 2006; Nugent vd., 2009; Lindh \& Holgersson 2007). Son olarak hedef odaklı yaklaşıma göre ise; çocuklar, çoğunlukla okul dışında gerçekleşen robotik turnuvalarında belirlenen problem durumları çerçevesinde rekabet ederek öğrenirler (FIRST Lego League, 2019; RoboCupJunior, 2019; MEB Robot Yarışması, 2019). 
Son on yılda hız kazanan eğitsel robotik etkinlikleri içeren sınıf içi çalışmalarda öğrenme ortamları ve öğrenci kazanımları bağlamında birbirinden farklı uygulamalar söz konusudur. İlgili literatür incelendiğinde; uygulamaların çoğunun ders dışı etkinlikler ş̧eklinde yürütüldüğü görülmektedir. Hussain vd. (2006) beşinci ve dokuzuncu sınıf öğrencileri ile yürüttüğü çalışmada, bir yıl boyunca düzenli LEGO eğitimi alan öğrencilerin okuldaki performanslarını incelemiş, LEGO eğitimi alan 5. sınıf öğrencilerinin almayanlara göre matematik dersinde daha başarılı olduklarını tespit etmiştir. Ayrıca öğrencilerin problem çözme becerilerinde anlamlı bir farklılık olmadığı, özellikle matematikte daha yetenekli olan öğrencilerin robotik etkinliklerine daha iyi adapte oldukları belirlenmiştir. Dokuzuncu sınıf öğrencilerinin matematik dersindeki başarılarında ve problem çözme becerilerinde LEGO robotik eğitiminin herhangi bir etkisi söz konusu değildir. Williams vd. (2007)'nin 21 ortaokul öğrencisi ile yaz kampı şeklinde yürüttüğü çalışmada, robotik aktivitelerinin Newton hareket kanunları bilgisi ve bilimsel sorgulama becerileri üzerindeki etkisi incelenmiş, uygulamanın öğrencilerin fizik bilgisini arttırdığı, ancak, bilimsel sorgulama becerilerini geliştirmede başarısız olduğu belirlenmiş̧ir. "Fizik öğretiminde Robotik" konulu başka bir araştırmada, 1şık ve ses ile ilgili uygulamalar geliştirilmiş, robotik destekli etkinlikleri kullanan öğrencilerin kullanmayanlara göre fizik dersindeki yeteneklerinin ve sosyal becerilerinin daha fazla geliştiği tespit edilmiştir. Bu çalışmaya göre, özellikle konsantrasyon güçlüğü çeken öğrenciler için katılım ve motivasyon açısından olumlu sonuçlar elde edilmiştir (Silva, 2008). Ulusal literatür incelendiğinde, sınırlı sayıda da olsa çeşitli araştırmalar mevcuttur. Robotikle ilgili öğrenci görüşlerinin belirlendiği ayrıca 7. sınıf "Kuvvet ve Hareket" ünitesinde robotik destekli yapılan etkinliklerin, öğrencilerin bilimsel süreç becerileri ve Fen ve Teknoloji dersine yönelik motivasyonlarına etkisinin incelendiği bir çalışmada, öğrencilerin robotikle ilgili görüşlerinin olumlu olduğu ve deney grubu öğrencilerinin bilimsel süreç becerileri ile derse yönelik motivasyonlarının anlamlı düzeyde arttığı belirlenmiştir (Şenol, 2012). Okkesim (2014)'in, 8. sınıf Fen ve Teknoloji dersi "Maddenin Halleri ve Isı" ünitesinde yaptığı uygulamada, on haftalık süreç sonunda deney grubu öğrencilerinin bilimsel süreç becerilerinin ve Fen ve Teknoloji dersine yönelik tutumlarının kontrol grubuna göre anlamlı düzeyde arttı̆̆ tespit edilmiştir. Uluslararası literatüre göre Türkiye'de daha az sayıda çalışma yapılmasının nedeni, araştırmacıların yazılımlardan kaynaklanan dil engelleri ve yüksek ürün fiyatları ile ilişkilendirilmektedir (Kazez ve Genç 2016). Fiyat engelini aşmak için bazı araştırmacılar Lego markalı ürünleri kullanmak yerine, yeni sistemler geliştirmeyi hedeflemişlerdir (Morris 2012). Ayrıca uygulamalar için gerekli eğitim ve teknik donanımın eksikliği, Türkiye'de robotik çalışmalarının yeterince yapılamamasının en büyük nedenlerinden biri olarak görülmektedir (Koç ve Büyük, 2013).

Kullanılan robotların somut birer yapı olmaları, gerçek üç boyutlu öğrenme ortamı sunmaları, sıfirdan öğrenciler tarafından tasarlanabilmeleri göz önüne alındığında, eğitsel robotiğin teknoloji tabanlı eğitici video, bilgisayar tabanlı modelleme ve simülasyon gibi uygulamalara göre daha etkili olduğu söylenebilir (Mitnik vd. 2009). Papert (1980) gibi eğitim teorisyenleri, eğitsel robotiğin arkasındaki ana teorinin yapılandırmacılık olduğunu, robotik faaliyetlerin sınıf öğretimini geliştirmek için muazzam bir potansiyele sahip olduğuna inanmaktadır. Bu özelliklerinden dolayı, robotik tabanlı öğrenme ortamlarının, öğrenciler için daha ilgi çekici olduğu, motivasyonu arttırdığı, daha derin keşifler için ortamlar sunduğu ve bilimsel kavramların anlaşılmasını kolaylaştırdığı belirlenmiştir. (Alimisis ve Boulougaris, 2014). Robotiğin eğitime katkı sağlama potansiyeli yüksek olmasına rağmen, sınıflarda yapılan basit robotik tanıtımları ile beklenen yararları sağlaması oldukça güçtür. Robotik, öğrenme ortamlarında mutlaka kullanılması gereken, öğrencilerin öğrenmesindeki anahtar rol oynayan uygulamalar olarak değerlendirilmemelidir. Asıl önemli olan nokta, öğretim programları içerisine bu tür uygulamaların doğru şekilde entegre edilebilmesidir (Alimisis, 2013). Literatürde sınırlı sayıda yapılmış çalışmalar incelendiğinde, robotik uygulamalarının beklenen faydayı sağlayabilmesi için matematik ve fen grubu öğretim programlarına uyarlanmasının önem arz ettiği belirlenmiştir. Bu çalışmanın amacı, 4. Sınıf Fen Bilimleri dersi kapsamındaki "Mikroskobik Canlılar ve Çevremiz" ünitesindeki kazanımlara yönelik hazırlanan robotik destekli uygulamaların 
öğrencilerin akademik başarı ve bilimsel süreç becerilerine etkisi olup olmadığını ortaya koymaktır. Çalışmada konu temelli öğretim programı yaklaşımı temel alınarak, kazanımlara uygun, araştırmasorgulamaya dayalı etkinlikler tasarlanmıştır. Fen bilimleri dersindeki kazanımlara uygun robotik ders tasarımının kullanılmış olması ve deneysel bir çalışma olması dolayısıyla yapılan bu çalışmanın alan literatürüne katkı sağlayacağı düşünülmektedir.

\section{Araştırma Soruları}

1. Robotik uygulamalarının yapıldığı deney grubu ile öğretim programına uygun öğretimin yapıldığ 1 kontrol grubu arasında akademik başarı erişi (sontest ile öntest arasındaki fark) değişkeni açısından anlamlı bir farklılık var mıdır?

2. Robotik uygulamalarının yapıldığı deney grubunun akademik başarı öntest ile sontest puanları arasında anlamlı bir farklilık var midır?

3. Öğretim programına dayalı uygulamanın yapıldı ğı kontrol grubu öğrencilerinin akademik başarı öntest ile sontest puanları arasında anlamlı bir farklılık var mıdır?

4. Robotik uygulamalarının yapıldığı deney grubu ile öğretim programına uygun öğretimin yapıldığ 1 kontrol grubu arasında bilimsel süreç becerileri erişi (sontest ile öntest arasındaki fark) değişkeni açısından anlamlı bir farklılık var mıdır?

5. Robotik uygulamalarının yapıldığı deney grubunun bilimsel süreç becerileri öntest ile sontest puanları arasında anlamlı bir farklılık var mıdır?

6. Öğretim programına dayalı uygulamanın yapıldığı kontrol grubu öğrencilerinin bilimsel süreç becerileri öntest ile sontest puanları arasında anlamlı bir farklılık var mıdır?

7. Robotik uygulamalarının yapıldığı deney grubu öğrencilerinin robotik destekli uygulamalar hakkındaki görüşleri nasıldır?

\section{Yöntem}

Belirtilen araştırma problemlerini incelemek için 2016-2017 eğitim-öğretim yılında gerçekleştirilmiş olan araştırmada deneysel yöntem kullanılmıştır. Deneysel yöntem, çoğu kez yapay bir durum oluşturularak değişkenler arasındaki sebep-sonuç ilişkisinin saptanması ve bulguları etkileyen etkenlerin belirlenmeye çalışılması şeklindeki bir araştırma türüdür (Çepni, 2007). Araştırma problemlerini test etmek için, deneysel yöntemler içerisinden yarı deneysel yöntem ve öntest-sontest kontrol gruplu desen kullanılmıştır. Eşleştirilmiş grupların seçkisiz bir şekilde deney grupları olarak atandığı çalışmalar yarı deneysel desenler olarak kabul edilir (Büyüköztürk vd. 2014). "Akademik başarı ve bilimsel süreç becerileri” bağımlı değişkenleri üzerindeki etkisi incelenen bağımsız değişken "robotik kodlama uygulamaları" dır.

Tablo1. Araştırma Deseninin Simgesel Görünümü

\begin{tabular}{llcl}
\hline \multicolumn{1}{c}{ Grup } & Ölçme I & İşlem & Ölçme II \\
\hline Deney & $\mathrm{ABT}_{1}$ & $\mathrm{X}_{1}$ & $\mathrm{ABT}_{2}$ \\
& $\mathrm{BSBT}_{1}$ & & $\mathrm{BSBT}_{2}$ \\
\multirow{2}{*}{ Kontrol } & $\mathrm{ABT}_{1}$ & $\mathrm{X}_{2}$ & $\mathrm{ABT}_{2}$ \\
& $\mathrm{BSBT}_{1}$ & & $\mathrm{BSBT}_{2}$ \\
\hline
\end{tabular}

D: Robotik uygulamalarının yapıldığı deney grubu.

K: Öğretim programına dayalı uygulamanın yapıldığı kontrol grubu. 
$\mathrm{X}_{1}$ : Robotik destekli etkinlik uygulamaları.

$\mathrm{X}_{2}$ : Öğretim programına uygun uygulamalar.

ABT: Mikroskobik Canlılar ve Çevremiz Ünitesine Yönelik Çoktan Seçmeli Akademik Başarı Testi

BSBT: Bilimsel Süreç Becerisi Testi.

\section{Çalışma Grubu}

Araştırmada Batı Karadeniz Bölgesinde bir ilçe merkezinde bulunan bir devlet okulunda öğrenim gören 4. Sınıf öğrencilerinden, seçkisiz olarak atanan iki deney ve iki kontrol grubu ile (87 öğrenci) çalışılmışıır. Okul seçimi sürecinde okulun bölgenin genel özelliklerini taşımasına, grup sayılarının yeterli olmasına ve altyapı kapasitesinin yeterli olmasına dikkat edilmiş̧ir. Deney gruplarına (44 öğrenci) robotik uygulamalarla desteklenmiş etkinlikler yapılırken, kontrol gruplarında (43 öğrenci) ise öğretim programının öngördüğ̈̈ yöntemler uygulanmıştır. Deney grupları 22 kız ve 22 erkek öğrenci, kontrol grupları ise 23 kız ve 20 erkek öğrenciden oluşmaktadır.

\section{Uygulama Basamakları}

Çalışmaya başlamadan önce, deney ve kontrol grubundaki öğrencilere ABT, BSBT ön testleri uygulanmıştır. Deney ve kontrol grupları seçkisiz olarak belirlendikten sonra, ilgili uygulama öğretmenlerine ve deney grubu öğrencilerine iki hafta boyunca "Serbest Etkinlikler" dersinde LEGO ${ }^{\circledR} \mathrm{WeDo}^{\mathrm{TM}}$ eğitim setinin kullanımı ile ilgili temel robotik eğitimi verilmiştir. Temel robotik eğitimi kapsamında ilk hafta robot setinin parçaları tanıtılmış, nasıl kullanılacağına dair bilgiler verilmiştir. İkinci hafta tasarlanan robotların nasıl programlanacağını örnek uygulamalar üzerinden gösterilmiştir. Bu iki hafta boyunca "Serbest Etkinlikler" dersinde kontrol grubu öğrencilerine öğretim programının öngördüğü etkinlikler uygulanmıştır.

Bu çalışmada "Mikroskobik Canlılar ve Çevremiz" ünitesi seçilmiştir. Bu ünitenin seçilme gerekçesi ünitenin kazanımlarının yapılacak olan robotik etkinlikleri ile uyumlu olduğunun düşünülmesidir. Kazanımlara yönelik uygulamalara başlamadan önce, her iki grup için öğretmen yönergeleri ve öğrenci çalışma kâğıtları hazırlanmıştır. Deney grubuna yönelik hazırlanan öğretmen yönergeleri ve öğrenci çalışma kâğıtlarının kullanıldığı her bir etkinlik, Fen Bilimleri dersi (4. sınıf) "Mikroskobik Canlılar ve Çevremiz" ünitesi kazanımları ile ilgili olup, LEGO® ${ }^{\mathrm{WeDo}}{ }^{\mathrm{TM}}$ robotik setlerinin kullanımını gerektirmektedir. Kontrol için aynı etkinlikler robot kullanımını gerektirmeyecek şekilde uyarlanmışlardır.

Ünite kazanımlarına yönelik uygulamalar öğretim programının öngördüğü şekilde, haftada 3 saat olmak üzere dört hafta boyunca devam etmiştir (toplam 12 saat). Uygulama araştırmac1 tarafından gerçekleştirilmiş olup, sınıf öğretmenleri derslere yardımcı olarak katılmışlardır. Deney grubu öğrencileri, robotik uygulamaları ile ünitenin kazanımlarını gerçekleştirmişler, ayrıca innovatif teknolojilerin nasıl geliştirileceği üzerine temel beceriler elde ederek uygulamaları tamamlamışlardır. Kontrol gruplarında, öğrenci merkezli ve öğretim programının öngördüğü etkinlik ve öğretim yöntem ve teknikleri kullanılarak dersler işlenmiştir.

Etkinliklerin tamamlandıktan sonraki hafta, deney ve kontrol grubu öğrencilerinin her ikisine de son test olarak ABT, BSBT uygulanmıştır. Araştırma öntest ve sontestlerin uygulanması ile birlikte (temel robotik eğitimi hariç) toplam 6 hafta devam etmiştir.

\section{LEGO® WeDo ${ }^{\text {TM }}$ Eğitim Seti}

Hazırlanan ders planlarında LEGO ${ }^{\circledR}$ Education $\mathrm{WeDo}^{\mathrm{TM}}$ eğitim seti kullanılmıştır. Bu set, çalışan motorlar ve sensörler içeren, LEGO ${ }^{\circledR}$ robotlarını geliştirmelerine imkan veren 8 ila 11 yaş arası çocuklar için tasarlanmış olan bir robot setidir. Yapı kiti, bir motor, eğim sensörü, hareket sensörü, bir LEGO ${ }^{\circledR}$ USB hub'1, dişliler ve çeşitli LEGO ${ }^{\circledR}$ tuğlalarını içeren, 150 'den fazla parçası 
olan bir settir. Bir robot yapıldıktan sonra, çocuklar USB hub'ı kullanarak robotlarını bilgisayara bağlar ve beraberindeki WeDo ${ }^{\mathrm{TM}}$ yazılımını kullanarak programlar oluşturur. Bu yazılım, LabVIEW тм tarafından desteklenen, blok tabanlı bir sürükle - bırak yazılımıdır. Bu tür yazılımlarda ekran programlama blokları, yapboz parçaları gibi bir araya getirilir (Elkin vd. 2014).

\section{Öğrenci Etkinlik Planları}

2013 yılında yürürlüğe giren Fen Bilimleri Dersi Öğretim Programının uygulanmasında, ilkokul üçüncü ve dördüncü sınıflarda yapılandırılmış araştırma-sorgulama, beşinci ve altıncı sınıflarda rehberli araştırma-sorgulama, yedinci ve sekizinci sınıflarda ise açık uçlu araştırma sorgulama yaklaşımı esas alınmıştır (MEB, 2013). Buna göre, yapılandırılmış sorgulamada öğretmen tarafından soru ve süreç verilir, öğrenci çözümü gerçekleştirir (Yıldırım ve Altan, 2017). Çalışma grubunu oluşturan öğrenciler dördüncü sınıf öğrencileri olduğundan deney grubunda yapılandırılmış araştırma sorgulamaya göre hazırlanan etkinlikler kullanılmıştır. Etkinlikler üç aşamadan oluşmaktadır; Birinci aşamada "Neden?" sorusunu kullanarak balık kılçığ 1 tekniği ile problem durumu ortaya konulmuştur. İkinci aşamada "Nasıl?" sorusu sorularak öğrencilerin çözüm için önerileri alınmıştır. Üçüncü aşamada ise "Ne Yapmalıyım?" sorusu ile, nasıl bir robotun yapılması gerektiği sorusuna cevap aranmıştır. Tüm aşamalarda öğrenciler, araştırmacının yönlendirmesi ile planlanan süreci uygulamaya çalışarak ve sonunda çözüme ulaşmaları beklenmiştir. Kontrol grubunda da yapılandırılmış araştırma sorgulamaya göre hazırlanan benzer etkinlikler kullanılmıştır. "Neden?", "Nasıl?" ve "Ne Yapmalıyım" soruları kullanılarak tasarlanan kontrol grubu etkinliklerinin deney grubundakilerden farklı olarak robotik içermemektedir.

\section{Etkinliklerin Uygulanması}

12 ders saatlik çalışma sürecinde deney grubuna 4 ayrı etkinlik uygulanmıştır. $\mathrm{Bu}$ etkinliklerden her biri Tablo 2'de verilen konu alanı ve kazanımlara uygun olarak tasarlanmıştır. Etkinlikler, yapılandırılmış araştırma sorgulamaya uygun olarak gerçekleştirilmiştir.

Tablo 2. Çalışma Grubu Etkinlikleri ve Kazanımları.

\begin{tabular}{cccc}
\hline Konu & $\begin{array}{c}\text { Etkinlik } \\
\text { No }\end{array}$ & Etkinlik Adı & Kazanım \\
\hline
\end{tabular}

1

Mikroskopların Tarihi Serüveni

4.5.1. Mikroskobik Canlıları Tanıyalım
4.5.1.1. Mikroskopun işlevini bilir.

4.5.1.2. Mikroskopun tarihsel süreç içerisindeki gelişiminini araştırır ve rapor eder.
Mikroskobun çalışma

2 Prensibi ve Genel Kullanım

Amac1

3 Daha Temiz Sokaklar

4.5.2. İnsan ve Çevre İlişkisi
4.5.1.3. Mikroskobik canlıların varlığını fark eder ve mikroskop yardımı ile bu canlıları gözlemler.

4.5.2.1. İnsan ve çevre arasındaki karşılıklı etkileşimin önemini kavrar.

4.5.2.2. Çevre kirliliğinin nasıl önlenebileceğini tartışır.

4.5.2.3. Çevre kirliliğini önlemek için yakın çevresini temiz tutar.

4.5.2.4. Çevreyi korumak ve güzelleştirmek için bir proje tasarlar. 


\section{Veri Toplama Araçları}

Veri toplama sürecince Akademik Başarı Testi, Bilimsel Süreç Becerileri Testi ve öğrenci günlükleri kullanılmıştır.

\section{Akademik Başarı Testi (ABT)}

Akademik başarı testi, Fen Bilimleri dersi öğretim programına göre, "Mikroskobik Canlılar ve Çevremiz" ünitesi içerisinde yer alan "Mikroskop ve mikroskobik canlılar" ve "Çevre kirliliği, çevreyi koruma ve güzelleştirme" konuları ile ilgili çoktan seçmeli sorulardan oluşmaktadır.

Konulara ait her kazanımla ilgili soruların eşit dağılmasına ve zorluk derecelerine dikkat edilmiş, ayrıca toplam dört uzmanın görüşüne başvurularak testin kapsam geçerliliği sağlanmıştır. Elli sorudan oluşan ilk akademik başarı testi; toplam 100 öğrenciye uygulanarak Iteman Programı ile güvenirlilik çalışmaları yapılmış, elde edilen veriler neticesinde, 31 soru ile başarı testine araştırmacı tarafindan son hali verilmiştir. Başarı testinde her soru eşit puanlı olup, alınabilecek en yüksek puan 100 'dür. Ön test ve son test olarak deney ve kontrol gruplarına 40 dakika süre ile uygulanan akademik başarı testinin Iteman güvenirlik değeri 0,79 olarak tespit edilmiştir.

\section{Bilimsel Süreç Becerileri Testi(BSBT)}

Smith ve Welliver (1990) tarafından geliştirilen bilimsel süreç beceri testinin Türkçeye adapte edilmesi Sabır (2016) tarafindan yapılmıştır. 4 seçenekli 40 maddeden oluşan test, bilimsel süreç becerilerinin 13 türünü (Gözlem yapma, sınıflama, ölçme ve sayıları kullanma, uzay/zaman ilişkilerini kullanma, çıkarım yapma, tahmin yapma, yaparak tanımlama, değişkenleri tanımlama, hipotez kurma, deney yapma, verileri yorumlama, iletişim kurma ve model oluşturma) ölçmektedir.

Testin kapsam geçerliği beş uzmanın görüşü alınarak sağlanmış olup KR-20 güvenirlik değeri 0,83 tür. Test 4 . ve 5. sinıfların bilimsel süreç becerilerini ölçmeye uygun olup (Sabır, 2016) deney ve kontrol gruplarına öntest ve sontest olarak 45 dakikalık sürede uygulanmıştır.

\section{Öğrenci Günlükleri}

Deney grubu öğrencilerinin robotik destekli uygulamaları yaparken yaşadığı zorlukları ve motivasyon durumlarını tespit etmek amacı ile “Öğrenci Günlükleri” kullanılmıştır.

\section{Verilerin Analizi}

Her iki gruba ait nicel veriler, öğrenci sayısı 50 nin altında olduğu için Shapiro Wilk normallik testine göre normal dağılım göstermektedir. Veriler SPSS paket programında bulunan parametrik istatistiklerden bağımlı ve bağımsız gruplar için t-testi yöntemleri ile analiz edilmiştir. Öğrenci günlüklerinden elde edilen nitel veriler ise betimsel analiz yöntemi ile incelenmiştir.

\section{Bulgular} konmuştur:

$\mathrm{Bu}$ bölümde araştırma sorularına göre elde edilen bulgular sırasıyla ele alınmış ve ortaya

1. araştırma sorusuna ilişkin bağımsız gruplar için t-testi analizi sonuçları Tablo 3' te gösterilmiştir:

Tablo 3. Deney ve Kontrol Grupları Akademik Başarı Erişi Puanları Bağımsız Gruplar İçin t- Testi Sonuçları.

\begin{tabular}{lllllll}
\hline Grup & $\mathbf{N}$ & $\mathbf{X}$ & $\mathbf{S}$ & $\mathbf{s d}$ & $\mathbf{T}$ & $\mathbf{P}$ \\
Deney & 44 & 7.77 & 7.2 & & & \\
Kontrol & 43 & 5.62 & 11.33 & 85 & 1.05 & .29 \\
\hline
\end{tabular}


Tablo 3'e göre, Robotik uygulamalarının yapıldığı deney grubu ile öğretim programına uygun öğretimin yapıldığı kontrol grubu arasında akademik başarı erişi puanları incelendiğinde, deney grubu puanlarının (7.77) kontrol grubuna (5.62) göre daha yüksek olduğu görülmektedir. Bu fark istatistiksel açıdan anlamlı değildir $\left(\mathrm{t}_{(85)}=1.05, \mathrm{p}>.05\right)$.

2. araştırma sorusuna ilişkin bağımsız gruplar için t-testi analizi sonuçları Tablo 4' te gösterilmiştir:

Tablo 4. Deney ve Kontrol Grupları Bilimsel Süreç Becerisi Erişi Puanları Bağımsız Gruplar İçin t- Testi Sonuçları.

\begin{tabular}{lllllll}
\hline Grup & $\mathbf{N}$ & $\mathbf{X}$ & $\mathbf{S}$ & $\mathbf{s d}$ & $\mathbf{T}$ & $\mathbf{P}$ \\
Deney & 44 & 10.34 & 13.12 & & & \\
Kontrol & 43 & 6.45 & 8.76 & 85 & 1.62 & .109 \\
\hline
\end{tabular}

Tablo 4'e göre, Robotik uygulamalarının yapıldığı deney grubu ile öğretim programına uygun öğretimin yapıldığı kontrol grubu arasında bilimsel süreç becerisi erişi puanları incelendiğinde deney grubu puanlarının (10.34) kontrol grubuna (6.45) göre daha yüksek olduğu görülmektedir. Bu fark istatistiksel açıdan anlamlı değildir $\left(\mathrm{t}_{(85)}=1.65, \mathrm{p}>.05\right)$. gösterilmiştir:

3. araştırma sorusuna ilişkin bağımlı gruplar için t-testi analizi sonuçları Tablo 5' te

Tablo 5. Deney Grubu Akademik Başarı Öntest-Sontest Puanları Bağımlı Gruplar İçin tTesti Sonuçları.

\begin{tabular}{lllllll}
\hline Ölçüm & $\mathbf{N}$ & $\mathbf{X}$ & $\mathbf{S}$ & $\mathbf{s d}$ & $\mathbf{T}$ & $\mathbf{p}$ \\
Öntest & 44 & 45.60 & 12.66 & & & \\
Sontest & & 53.37 & 12.77 & 43 & 7.15 & .00 \\
\hline
\end{tabular}

Robotik uygulamalarının yapıldığ deney grubunun akademik başarı öntest -sontest puanları arasında anlamlı bir farklılık vardır $\left(\mathrm{t}_{(43)}=7.15, \mathrm{p}<.05\right)$. Deney grubu öğrencilerinin ABT ön test puanları ortalaması 45,60 , son test puanları ortalaması ise 53,37 olarak tespit edilmiştir. Bu bulguya göre farklılık deney grubu son test puanları lehinedir.

4. araştırma sorusuna ilişkin bağımlı gruplar için t-testi analizi sonuçları Tablo 6' te gösterilmiştir:

Tablo 6. Deney Grubu Bilimsel Süreç Becerisi Öntest-Sontest Puanları Bağımlı Gruplar İçin t-Testi Sonuçları.

\begin{tabular}{lllllll}
\hline Ölçüm & $\mathbf{N}$ & $\mathbf{X}$ & $\mathbf{S}$ & $\mathbf{s d}$ & $\mathbf{T}$ & $\mathbf{p}$ \\
Öntest & 44 & 52.04 & 13.2 & & & \\
Sontest & & 62.38 & 12.0 & 53 & 5.22 & .00 \\
\hline
\end{tabular}

Robotik uygulamalarının yapıldığı deney grubunun bilimsel süreç becerisi öntest -sontest puanları arasında anlamlı bir farklılık vardır $\left(\mathrm{t}_{(53)}=5.22, \mathrm{p}<.05\right)$. Deney grubu öğrencilerinin BSBT 
ön test puanları ortalaması 52,04, son test puanları ortalaması ise 62,38 olarak tespit edilmiştir. Bu bulguya göre farklılık deney grubu son test puanları lehinedir.

5. araştırma sorusuna ilişkin bağımlı gruplar için t-testi analizi sonuçları Tablo 7' te gösterilmiştir:

Tablo 7. Kontrol Grubu Akademik Başarı Öntest-Sontest Puanları Bağımlı Gruplar İçin tTesti Sonuçları.

\begin{tabular}{lllllll}
\hline ÖIçüm & $\mathbf{N}$ & $\mathbf{X}$ & $\mathbf{S}$ & $\mathbf{S d}$ & $\mathbf{T}$ & $\mathbf{p}$ \\
Öntest & 43 & 57.23 & 15.06 & 42 & & \\
Sontest & & 62.86 & 14.22 & & 3.25 & .00 \\
\hline
\end{tabular}

Öğretim programına dayalı uygulamalarının yapıldığ öntest -sontest puanları arasında anlamlı bir farklılık vardır $\left(\mathrm{t}_{(42)}=3.25, \mathrm{p}<.05\right)$. Kontrol grubu öğrencilerinin ABT ön test puanları ortalaması 57,23, son test puanları ortalaması ise 62,86 olarak tespit edilmiştir. Bu bulguya göre farklılık kontrol grubu son test puanları lehinedir.

6. araştırma sorusuna ilişkin bağımlı gruplar için t-testi analizi sonuçları Tablo 8' te gösterilmiştir:

Tablo 8. Kontrol Grubu Bilimsel Süreç Becerisi Öntest-Sontest Puanları Bağımlı Gruplar İçin t-Testi Sonuçları.

\begin{tabular}{lllllll}
\hline Ölçüm & $\mathbf{N}$ & $\mathbf{X}$ & $\mathbf{S}$ & $\mathbf{s d}$ & $\mathbf{T}$ & $\mathbf{p}$ \\
Öntest & 43 & 55.69 & 12.5 & 42 & & \\
Sontest & & 62.15 & 12.61 & & 4.82 & .00 \\
\hline
\end{tabular}

Öğretim programına dayalı uygulamalarının yapıldığ 1 kontrol grubunun bilimsel süreç becerisi öntest -sontest puanları arasında anlamlı bir farkl1lık vardır $\left(\mathrm{t}_{(42)}=4.82, \mathrm{p}<.05\right)$. Kontrol grubu öğrencilerinin BSBT ön test puanları ortalaması 55,69, son test puanları ortalaması ise 62,15 olarak tespit edilmiştir. Bu bulguya göre farklılık kontrol grubu son test puanları lehinedir.

\section{Sonuç ve Tartışma}

Araştırma bulgularına göre ulaşılan sonuçlar şu şekildedir: Robotik kodlama uygulamalarının yapıldığı deney grubu ile Fen bilimleri öğretim programına uygun öğretimin yapıldığı kontrol grubu arasında akademik başarı erişi puanları açısından anlamlı bir fark bulunamamıştır. Ancak yine de deney grubu ögrencilerinin akademik başarı erişi puanlarının, kontrol grubu öğrencilerinin akademik başarı erişi puanlarının göre daha yüksek olduğu sonucuna ulaşılmıştır. Benzer sonuçlar Hussain vd. (2006) ve Lindh ve Holgersson (2007) tarafindan da elde edilmiştir. Hussain vd (2006) bir yı boyunca düzenli LEGO eğitimi alan 9. sınıf öğrencilerinin bu eğitimi almayan öğrencilere göre matematik başarılarında anlamlı bir fark oluşmadğını, Lindth ve Holgersson (2007) de robotik uygulamalrının 5. ve 9. Sınıf öğrencilerinin matematik ve mantuk sorusu çözme kabiliyetlerini anlamlı düzeyde arttırmadığını rapor etmiştir.

Araştırma bulgularına bakıldığında, robotik kodlama uygulamalarının kullanıldığı deney grubu ile fen bilimleri dersi (4.sınıf) öğretim programına uygun yöntemlerin kullanıldı̆̆ 1 kontrol grubu öğrencilerinin akademik başarı ön test ve son test puanları arasında anlamlı bir fark olduğu sonucuna ulaşı1mıştır. Her iki grubun son test akademik başarı puanları ön test akademik başarı puanlarına göre daha yüksek çıkmıştır. Bu sonuca göre hem robotik kodlama uygulamalarının hem de öğretim programına uygun yöntemlerin öğrencilerin akademik başarılarının artmasında etkili 
olmuştur. Her iki grupta da yapılandırılmış araştırma sorgulamaya göre hazırlanan benzer etkinliklerin kullanılmış olması, akademik başarı erişi puanları arasında anlamlı bir farkın oluşmamasında etkili olduğu düşünülmektedir.

Robotik kodlama uygulamalarının yapıldığı deney grubu ile Fen bilimleri öğretim programına uygun öğretimin yapıldığı kontrol grubu arasında bilimsel süreç becerisi erişi puanları açısından anlamlı bir fark bulunamamıştır. Ancak yine de deney grubu öğrencilerinin bilimsel süreç becerisi erişi puanlarının, kontrol grubu öğrencilerinin bilimsel süreç becerisi erişi puanlarının göre daha yüksek olduğu sonucuna ulaşılmıştır. Ayrıca robotik kodlama uygulamalarının kullanıldığ deney grubu ile fen bilimleri dersi (4.sınıf) öğretim programına uygun yöntemlerin kullanıldığ kontrol grubu öğrencilerinin bilimsel süreç becerisi ön test ve son test puanları arasında anlamlı bir fark olduğu sonucuna ulaşılmıştır. Her iki grubun son test bilimsel süreç becerisi puanları ön test bilimsel süreç becerisi puanlarına göre daha yüksek çıkmıştır. Bu sonuca göre hem robotik kodlama uygulamalarının hem de öğretim programına uygun yöntemlerin öğrencilerin bilimsel süreç becerilerinin artmasında etkili olmuştur. Her iki grupta da yapılandırılmış araştırma sorgulamaya göre hazırlanan benzer etkinliklerin kullanılmış olması, bilimsel süreç becerisi erişi puanları arasında anlamlı bir farkın oluşmamasında etkili olduğu düşünülmektedir.

Robotik etkinliklerinin başarı ve bilimsel süreç becerilerine olan etkisinin incelendiği literatürdeki diğer çalışmalara bakıldığında farklı bulgulara rastlamak mümkündür. Lindh ve Williams vd. (2007) ortaokul öğrencileri ile yaptığı başka bir çalışmada, iki haftalık uygulama sonunda öğrencilerin fizik konuları (Newton'un Hareket Kanunları) ile ilgili bilgilerinin artığını, bilimsel süreç becerilerinde anlamlı bir fark gözlenmediğini rapor etmiştir. Diğer taraftan Şenol ve Böyük (2015) yedinci sınıf öğrencileri ile gerçekleştirdikleri sekiz haftalık çalışmada, robotik destekli laboratuar uygulamalarının gerçekleştirildiği deney grubundaki öğrencilerin, fen bilimleri öğretim programına uygun öğrenim gören kontrol grubu öğrencilerine göre Bilimsel Süreç Becerilerinin anlamlı düzeyde daha yüksek olduğunu bulmuştur. Benzer bir şekilde Özdoğru (2013) altıncı sınıf öğrencileri ile gerçekleştirdiği çalışmanın sonucunda, Lego program tabanlı fen ve teknoloji eğitiminin öğrencilerin akademik başarılarına ve bilimsel süreç becerilerine olumlu etkisini rapor etmiştir.

Deney grubu öğrencilerinin her etkinlik sonunda doldurdukları öğrenci günlükleri incelendiğinde, uygulama süreci ile ilgili veriler elde edilmiştir. Öğrencilere robotik destekli etkinliklerin eğlenceli olup olmadığı, karşılaştıkları zorluklar, etkinlik boyunca ne öğrendikleri ve grup çalışmasında elde ettiği kazanımlar ile ilgili sorular sorulmuştur.

Öğrencilerin verdikleri cevaplar incelendiğinde ilk haftalarda daha önce robotik etkinlikleri yapmadıkları için heyecanlandıkları ama eğlenceli bulduklarını, ilk etkinliklerde robotun parçalarını tanımadıkları için zaman yönetimi konusunda sıkıntı yaşadıklarını, genel anlamda konu kazanımları ile ilgili bilgi sahibi olduklarını ve grup çalışmasının faydalı olduğunu ifade etmişlerdir. Son haftalarda ise, öğrencilerin robot setinin parçalarına daha hakim olduklarını, bunun sonucu olarak süre ile ilgili sorunların aşıldığından dolayı robotlara farklı kodlar yazarak daha çok eğlendiklerini ifade etmişlerdir. Ayrıca etkinlik sürecinin grup ilişkilerini geliştirdiğini vurgulamışlardır.

Günlüklerden elde edilen verilere göre, ilk haftalarda etkinlik süresinin büyük bölümünü robotu birleştirmek için harcadıklarını söyleyebiliriz. Bunun sonucunda öğrencilerin konu kazanımları yerine, robot yapım sürecine odaklandıkları sonucu çıkarılabilir. İlerleyen haftalarda ise robot tasarlama becerileri arttığ 1 için etkinliği yetiştirme sorunu ortadan kalkmasına rağmen, konu kazanımına odaklanmak yerine farklı kodlar yazarak etkinliği oyun olarak algıladıkları sonucu çıkarılabilir. Deney ve kontrol grubunun akademik başarı erişi puanları arasında anlamlı bir farkın çıkmamasının nedeni, öğrenci günlüklerinden elde edilen bulgular doğrultusunda, robot kodlama sürecinin ders konularının öğretim sürecinin önüne geçmesi olarak açıklanabilir. 
Sabır (2016)'a göre öğrencilerin sınıf seviyesi arttıkça bilimsel süreç becerilerini edinebilme düzeylerinin de artmaktadır. Elde ettiği sonuçlara göre 5. Sınıf öğrencilerinin bilimsel süreç beceri düzeylerinin 4. sınıfların düzeyinden yüksek olmasının nedeni öğrencilerin 11-12 yaş aralığında somut yaşantı döneminden soyut yaşantı dönemine geçiş aşamasında olmaları olabileceğini söylemiştir. Bir başka araştırmada Saraçoğlu vd. (2012) 4 ve 5. sınıf öğrencilerinin bilimsel süreç beceri düzeylerini karşılaştırmalı olarak incelemişler ve sınıf düzeyine göre puanlar anlamlı bir farklı1ık tespit edememişlerdir. Araştırmacılar bu sonucun nedenini, ilköğretim 4. ve 5. sınıf fen ve teknoloji dersi kazanımları içinde bilimsel süreç becerileri kazanımlarının birbirine yakın oranda temsil edilmemesine bağlamışlardır. Bu çalışmada deney ve kontrol grubunun bilimsel süreç becerileri erişi puanları arasında anlamlı bir fark olmaması literatürdeki bu bulgularla açıklanabilir.

Ayrıca hazırlanan robotik destekli etkinlikler 4. Sınıf düzeyine uygun olarak hazırlandıkları için, doğası gereği bütünleştirici bilimsel süreç becerilerini (yaparak tanımlama, değişkenleri tanımlama, hipotez kurma, deney yapma, verileri yorumlama, iletişim kurma ve model oluşturma) birçoğunu geliştirici nitelikte değildir. Deney ve kontrol grubunun bilimsel süreç becerileri erişi puanları arasında anlamlı bir fark olmamasında bu etkenin önemli rolü olduğu düşünülmektedir.

\section{Öneriler}

Robot kodlama sürecinin, konu kazanımlarının önüne geçmesini engellemek için öğrencilerin Fen Bilimleri dersi dışında robot setleri ile daha fazla zaman geçirmeleri sağlanarak kodlama becerileri arttırılabilir. Böylece öğrencilerin kodlama için harcayacakları zaman azaltılıp kazanımlara odaklanmaları sağlanarak, akademik başarının arttırılabilir. Akademik başarı düzeyi farklı olan öğrenciler ile uygulama tekrar edilerek, robotik destekli uygulamaların farklı düzeydeki öğrencilerin akademik başarılarına etkisi daha ayrıntılı olarak incelenebilir.

Bilimsel süreç becerilerini edinebilme düzeyinin sınıf düzeyi arttıkça arttığını göz önünde bulundurularak daha üst sınıflarla, uygun konular tespit edilerek çalışma yapılabilir. Etkinlikler tasarlanırken bütünleştirici bilimsel süreç becerilerini geliştirici nitelikte olasına özen gösterilmelidir. Bilimsel süreç becerileri düzeyi farklı olan öğrenciler ile uygulama tekrar edilerek, robotik destekli uygulamaların farklı düzeydeki öğrencilerin bilimsel süreç becerine etkisi daha ayrıntılı olarak incelenebilir.

2013 programda 4. sınıf "Mikroskobik Canlıları ve Çevremiz" ünitesinde yer alan konular, 2018 programında 5. sınıf düzeyinde "Insan ve Çevre" ve "Canlılar Dünyası" isimli iki ayrı ünitede yer bulmuştur. Robotik etkinliklerin öğrencilerin akademik başarılarını ve bilimsel süreç becerilerini geliştirdiği göz önüne alındığında, bu çalışmada geliştirilen etkinliklerin yeni programda da uygulanabilir. Ayrıca MEB 2023 vizyon belgesinde "Öğrenme Süreçlerinde Dijital İçerik ve Beceri Destekli Dönüşüm” bölümünde, önümüzdeki 3 yıllık dönemde ilkokul, ortaokul ve lise seviyelerinde, okulda ve okul dışında öğrenciye, öğretmene, eğitim yöneticilerine, kamuya, fen bilimleri öğretim programına, eğitsel içeriğe vb. yönelik yapılacak çalışmalarla kodlama, 3D tasarım, elektronik tasarım benzeri bilişimle üretim becerilerinin öğrenme süreçlerine entegrasyonu sağlanacağı vurgulanmıştır. Bu bağlamda çalışmanın katkı sağlayacağı düşünülmektedir.

Entegrasyon çalışmaları kapsamında, öğretmenlere robotik kodlama becerilerinin kazandırılmasına yönelik hizmet öncesi ve hizmet içi eğitim verilmeli, okulların robotik uygulamalar için fiziki şartlar hazırlanmalıdır. Robotik uygulamalarının ders kazanımlarıyla ilişkilendirilmesi hususunda çalışmalar yapılarak öğretmen adayları ve öğretmenler eğitilmelidir. Robotik uygulamaları sadece Fen Bilimleri derslerine değil tüm derslere entegre edilerek disiplinler arası anlayışla geliştirilmelidir. Robotik destekli etkinliklerin kullanılmasını yaygınlaştırmak amacıyla da elde edilen veriler ortak bir platform ve arşiv oluşturularak öğretmen ve öğrencilerin kullanımına sunulabilir. 


\section{Kaynakça}

Alimisis, D. (2013). Educational robotics: Open questions and new challenges, Themes in Science and Technology Education, 6(1), 63-71.

Alimisis, D., \& Boulougaris, G. (2014). Robotics in physics education: Fostering graphing abilities in kinematics. In Proceedings from the 4th international workshop teaching robotics: Teaching with robotics \& 5th international conference robotics in education (pp. 2-10).

Benitti, F. B. V. (2012). Exploring the educational potential of robotics in schools: A systematic review. Computers \& Education, 58(3), 978-988. https://doi.org/10.1016/j.compedu.2011.10.006

Büyüköztürk, Ş., Kılıç Çakmak, E., Akgün, Ö.E., Karadeniz, Ş., \& Demirel, F. (2011). Bilimsel araştırma yöntemleri. Ankara: Pegem. https://doi.org/10.14527/9789944919289

Çepni, S. (2007). Araştırma ve proje çalışmalarına giriş. Celepler Matbaacılık.

Eguchi, A. (2010). What is educational robotics? Theories behind it and practical implementation. In D. Gibson \& B. Dodge (eds.), Proceedings of Society for Information Technology \& Teacher Education International Conference 2010 (pp. 4006-4014). Chesapeake, VA: AACE.

Elkin, M., Sullivan, A., \& Bers, M. U. (2014). Implementing a robotics curriculum in an early childhood Montessori classroom. Journal of Information Technology Education: Innovations in Practice, 13, 153-169. https://doi.org/10.28945/2094

Erbaş, S. K. (2014). Temel Robotik Uygulamalar Ve Bilgisayar Destekli Tasarım Eğitimindeki Yeri, Ĕ̈itim ve Ögretim Araştırmaları Dergisi, 3(3): 304-3012.

Felicia, A. \& Sharif, S. (2014). A Review on Educational Robotics as Assistive Tools for Learning Mathematics and Science. International Journal of Computer Science Trends and Technology (IJCST), 2(2), 62-84.

FIRST Lego League. (2019). Retrived October 7, http://www.firstlegoleague.org/

Hussain, S., Lindh, J., \& Shukur, G. (2006). The effect of LEGO training on pupils'school performance in mathematics, problem solving ability and attitude: Swedish data.Journal of Educational Technology and Society, 9(3), 182-194.

Johnson, J. (2003). Children, robotics, and education. Artificial Life and Robotics, 7(1-2), 16-21.

Kazez, H. \& Genç, Z. (2016). İlkokul Matematik Öğretiminde Yeni Bir Yaklaşım Lego MoretoMath. Öğretim Teknolojileri ve Öğretmen Ĕgitimi Dergisi, 5(2): 33-39.

Koç, A \& Böyük, U. (2013). Fen ve Teknoloji Eğitiminde Teknoloji Tabanlı Öğrenme Robotik Uygulamaları. Türk Fen Eğitimi Dergisi, 10, (1): 139-155.

Laughlin, S. R. (2013). Robotics: Assessing its role in improving mathematics skills for grades 4 to 5 (Doctoral dissertation, Capella University).

Lindh, J. and Holgersson, T. (2007). Does LEGO training stim-ulate pupils' ability to solve logical problems, Computersand Education, 49(4), 1097-1111. https://doi.org/10.1016/j.compedu.2005.12.008

MEB Robot Yarışmas1. (2019). Retrived October 7, http://robot.meb.gov.tr/

MEB. (2013). İlköğretim Kurumları (İlkokullar ve Ortaokullar) Fen Bilimleri Dersi, (ilkokul ve ortaokul 3, 4, 5, 6, 7, 8. sınıflar). Temel Eğitim Genel Müdürlüğü.

Mitnik, R., Nussbaum, M. \& Soto, A. (2008). An autonomous educational mobile robot mediator, Auton Robot 25(4): 367-382. https://doi.org/10.1007/s10514-008-9101-z. 
Mitnik, R., Recabarren, M., Nussbaum, M., \& Soto, A. (2009). Collaborative robotic instruction: A graph teaching experience. Computers \& Education, 53(2), 330-342. https://doi.org/10.1016/j.compedu.2009.02.010

Morris, P. (2012). Listening and Legos ${ }^{\mathrm{TM}}$. International Journal of Listening, 26(2), 94-97.

Nugent, G., Barker, B., Grandgenett, N., \& Adamchuk, V. (2009). The use of digital manipulatives in k-12: robotics, GPS/GIS and programming. InFrontiers in educationconference, 2009. FIE'09. 39th IEEE(pp. 1-6, 18-21). https://doi.org/10.1109/fie.2009.5350828

Okkesim, B. (2014). Fen ve Teknoloji Öğretiminde Robotik Uygulamaları. Yüksek Lisans Tezi, Erciyes Üniversitesi, Eğitim Bilimleri Enstitüsü, Kayseri.

Özdoğru, E. (2013). Fiziksel olaylar öğrenme alanı için lego program tabanlı fen ve teknoloji eğitiminin öğrencilerin akademik başarılarına, bilimsel süreç becerilerine ve fen ve teknoloji dersine yönelik tutumlarına etkisi. Yüksek Lisans Tezi, Dokuz Eylül Üniversitesi Eğitim Bilimleri Enstitüsü, İzmir.

Papert, S. (1980). Mindstorms: Computers, Children and Powerful Ideas. Basic Books.

RoboCupJunior . (2019). Retrived October 7, http://www.robocupjunior.org

Sabır, A. (2016). İlköğretim 4. ve 5. Sınıf Öğrencilerinin Bilimsel Süreç Becerilerine Etki Eden Faktörlerin İncelenmesi. Yüksek Lisans Tezi, Mustafa Kemal Üniversitesi, Sosyal Bilimler Enstitüsü, Hatay.

Saraçoğlu, S., Böyük, U., \& Tanık, N. (2012). Birleştirilmiş ve bağımsız sınıflarda öğrenim gören ilköğretim öğrencilerinin bilimsel süreç beceri düzeyleri. Türk Fen Eğitimi Dergisi, 9(1), 83100.

Silva, J. M. V. D. (2008). Robótica no ensino da fisica, Tese de Mestrado, 4 de Fevereiro de 2008, http://hdl.handle.net/1822/8069.

Smith, K. A., \& Welliver, P. W. (1990). The development of a science process assessment for fourthgrade students. Journal of Research in Science Teaching, 27(8), 727-738. https://doi.org/10.1002/tea.3660270803

Sullivan, F. R. (2008). Robotics and science literacy: thinking skills, science process skills and systems understanding, Journal of Research in Science Teaching, 45(3), 373-394. https://doi.org/10.1002/tea.20238

Şenol, A. K. (2012). Robotik Destekli Fen ve Teknoloji Laboratuvar Uygulamalarl: Robolab, Yüksek Lisans Tezi, Erciyes Üniversitesi, Eğitim Bilimleri Enstitüsü, Kayseri.

Şenol, A., K. \& Büyük, U. (2015). Robotik Destekli Fen ve Teknoloji Laboratuvar Uygulamaları: ROBOLAB, Turkish Studies - International Periodical for the Languages, Literature and History of Turkish or Turkic Volume 10/3 Winter 2015, p. 213-236, ISSN: 1308-2140, www.turkishstudies.net, DOI Number: http://dx.doi.org/10.7827/TurkishStudies.7953.

Williams, D., Ma, Y., Prejean, L., Lai, G., \& Ford, M. (2007). Acquisition of physics content knowledge and scientific inquiry skills in a robotics summer camp, Journal of Research on Technology in Education, 40(2), 201-216. https://doi.org/10.1080/15391523.2007.10782505

Yıldırım, M., \& Altan, S. T. (2017). Araştırma ve sorgulamaya dayalı öğrenme yaklaşımının ilkokul öğrencilerinin bilimsel süreç becerilerine etkisi. Mustafa Kemal Üniversitesi Sosyal Bilimler Enstitüsü Dergisi, 14(38), 71-89. 